Artigo

\title{
Estudo dos Padrões de Ventos Offshore no Litoral do Ceará Utilizando Dados Estimados pelo Produto de Satélites BSW
}

\author{
Greicy Kelly da Silva ${ }^{1}$, Antônio Carlos Santana dos Santos ${ }^{1}$, Marx Vinicius Maciel da Silva ${ }^{1}$, \\ José Maria Brabo Alves ${ }^{1}$, Augusto César Barros Barbosa ${ }^{1}$, Cristiano de Oliveira Freire ${ }^{1}$, \\ Clênia Rodrigues Alcântara ${ }^{2}$, Sérgio Sousa Sombra ${ }^{1}$ \\ ${ }^{1}$ Mestrado Acadêmico em Ciências Físicas Aplicadas, Centro de Ciências e Tecnologia, \\ Universidade Estadual do Ceará, Fortaleza, CE, Brasil. \\ ${ }^{2}$ Unidade Acadêmica de Ciências Atmosféricas, Centro de Tecnologia e Recursos Naturais, \\ Universidade Federal de Campina Grande, Campina Grande, PB, Brasil.
}

Recebido em 22 de Maio de 2017 - Aceito em 29 de Setembro de 2017

\begin{abstract}
Resumo
Conhecer a distribuição espacial dos padrões de vento de uma região costeira para monitoramento do potencial eólico onshore e offshore passa pela existência de uma rede de estações meteorológicas no litoral. No litoral cearense, em decorrência de uma sistemática ausência desta rede, o estudo dos ventos costeiros pode se beneficiar com a utilização dos ventos a 10 m estimados por satélites, BSW, com resolução espacial e temporal de $0,25^{\circ}$ e seis horas, respectivamente. Neste trabalho, os ventos BSW são validados na vizinhança do litoral cearense através de boias oceânicas e torres anemométricas. Verificada sua acurácia, estes dados são utilizados para estudar a variabilidade espacial dos ventos marítimos no litoral cearense, em escala sazonal e interanual, e suas correlações com os ventos costeiros.
\end{abstract}

Palavras chave: ventos offshore, satélite, litoral.

\section{Study of the Offshore Wind Patterns on the Ceará Coast Using Estimated Data for the BSW Satellites Product}

\begin{abstract}
To know the spatial distribution of the wind patterns of a coastal region for monitoring the onshore and offshore wind potential goes through to the existence of a network of meteorological stations on the coast. On the coast of Ceará, a systematic analysis of the results obtained through prospective studies can be beneficial with the use of the results at $10 \mathrm{~m}$ estimated by satellites, BSW, with spatial and temporal resolution of $0.25^{\circ}$ and six hours, respectively. In this work, BSW winds are validated in the vicinity of the coast of Ceará through oceanic buoys and anemometric towers. Verified its accuracy, these data are used to study spatial variability of sea winds in Ceará, in seasonal and interannual scale, and their correlation with the coastal winds.
\end{abstract}

Keywords: offshore winds, satellite, coast.

\section{Introdução}

O Estado do Ceará está localizado em uma área com contínua circulação de ventos alísios que são intensificados por fenômenos de mesoescala como a brisa marítima, sendo, portanto, uma região de rico potencial energético (SEINFRA, 2001; Teixeira, 2008). A magnitude dos ventos alísios é afetada também pela presença do continente, entretanto, o Oceano Atlântico institui uma extensa área da costa do Estado do Ceará, livre de obstáculos, o que origi- nam ventos alísios com notável intensidade, constância e baixa turbulência. Estes ventos, com destacada componente onshore, quando atuantes em costas com relevo pouco acidentado, como é o caso da costa cearense, determinam fortemente os ventos costeiros continentais.

A energia eólica no Estado viabiliza a complementaridade sazonal quando aliada ao regime hídrico, visto que seu potencial máximo ocorre em períodos de baixos níveis dos reservatórios, Rocha et al. (1999). Com o intuito de

Autor de correspondência: Greicy Kelly da Silva, greicy.silva@aluno.uece.br. 
promover uma otimização desses recursos eólicos, promovendo uma estabilização sazonal da oferta de energia, faz-se necessário o conhecimento minucioso dos padrões de ventos e sua variabilidade espaço-temporal. No entanto, a baixa quantidade de estações meteorológicas no litoral do Estado limita consideravelmente a obtenção destas informações. Neste trabalho, utilizam-se os dados de ventos a $10 \mathrm{~m}$ estimados pelo produto do conjunto de satélites Blended Sea Winds (BSW), uma vez verificada sua acurácia, para entender estes padrões e variabilidades no litoral cearense.

O BSW é administrado pela National Oceanic and Atmospheric Administration (NOAA) e caracteriza os ventos oceânicos em escala global através da interpolação de dados obtidos de vários sensores, a bordo de satélites de órbita baixa, como o DMSP/SSMI, TMI, QuikSCAT e AMSR-E (Zhang, Reynolds e Bates, 2006), por exemplo. Os dados são disponibilizados para download com resolução temporal de quatro dados por dia nos horários sinóticos de 00 h, 06 h, 12 h e 18 h, em formato netcdf e em grade espacial com resolução de $0,25^{\circ} \times 0,25^{\circ}$, aproximadamente $27,5 \mathrm{~km}$. A priori, nos horários sinóticos, os dados de velocidades estimados por satélites individuais são interpolados para grade de $0,25^{\circ}$, detalhes do processo são encontrados em Zhang, Reynolds e Bates (2006).

Dados de ventos à superfície do oceano estimados por satélites tem sido amplamente usados na produção de reanálises. Como os ventos BSW estão em grade regularmente espaçada e nos horários sinóticos, podem ser utilizados, uma vez verificado sua confiabilidade, na compreensão dos padrões de ventos sinóticos e de mesoescala de uma região. Os ventos BSW também podem ser utilizados como informação de escala sinótica em modelos que estimam potencial eólico, como o WASP (Wind Atlas Analysis and Application Program), tanto na estimativa do potencial eólico offshore quanto onshore.

Este trabalho apresenta um estudo sobre a habilidade dos dados de ventos estimados pelo produto do conjunto de satélites BSW em representar os ventos oceânicos no Litoral Cearense. Em sequência, utiliza-se o BSW para estudar a amplitude das variações sazonais e interanuais destes ventos.

\section{Material e Métodos}

Inicialmente foi realizada a validação dos ventos BSW. Para validá-los utilizaram-se os dados de ventos medidos a $4 \mathrm{~m}$ por três boias do Projeto Pilot Research Moored Array in the Tropical Atlantic (PIRATA) localizadas no Oceano Atlântico $\left(0^{\circ} \mathrm{N}, 35^{\circ} \mathrm{W} ; 0^{\circ} \mathrm{N}, 23^{\circ} \mathrm{W}\right.$ e $4^{\circ} \mathrm{N}, 38^{\circ} \mathrm{W}$ ) para o período de 15 de dezembro de 1997 à 15 de setembro de 2011. Para nivelar os dados de vento medidos nas boias oceânicas com os do BSW aplicou-se uma correção logarítmica, extrapolando os dados medidos pelas boias de $4 \mathrm{~m}$ para $10 \mathrm{~m}$ e assumindo uma atmosfera estaticamente neutra. No entanto, as boias selecionadas são relativamente distantes do Litoral Cearense. Em virtude disto, foi realizada também uma comparação do BSW com três torres anemométricas litorâneas localizadas em Camocim $\left(40,88^{\circ} \mathrm{W}, 2,86^{\circ} \mathrm{S}\right)$, Icapuí $\left(37,31^{\circ} \mathrm{W}, 4,73^{\circ} \mathrm{S}\right)$ e Paracuru $\left(38,98^{\circ} \mathrm{W}, 3,41^{\circ} \mathrm{S}\right)$, sendo os dados medidos a $20 \mathrm{~m}, 40 \mathrm{~m}$ e $20 \mathrm{~m}$ da superfície, respectivamente. Para as torres de Camocim e Paracuru, utilizaram-se os dados de ventos para o ano de 2005, enquanto que para a torre de Icapuí, dados de 2007. A comparação do BSW com torres anemométricas fornece informações adicionais sobre a capacidade do BSW de reproduzir as tendências observadas nos ventos costeiros. As boias e torres utilizadas na validação e suas localizações são mostradas na Fig. 1 .

Após a validação utilizaram-se os dados mensais do BSW para o período de 15 de julho de 1987 à 15 de setembro de 2011, para estudar os padrões climatológicos dos ventos superficiais nas vizinhanças do litoral cearense, região limitada pelas coordenadas $6^{\circ} \mathrm{S}, 1^{\circ} \mathrm{N}$ e $42^{\circ} \mathrm{W}$, $34^{\circ} \mathrm{W}$. Em seguida, comparou-se os padrões de vento para dois anos 2009 e 2010, ano chuvoso e seco, respectivamente, sendo a área escolhida para caracterização destes ventos superficiais, o litoral cearense dividido em quinze pontos no Oceano Atlântico, equidistantes (aproximadamente $40 \mathrm{~km}$ ) e à aproximadamente $27 \mathrm{~km}$ da costa, conforme a Fig. 2. A escolha destes dois anos tem como objetivo estimar a amplitude das variações sazonais e interanuais ao longo da costa.

\section{Resultados e Discussão}

\subsection{Validação dos dados}

\subsubsection{Dados BSW vs. boias oceânicas}

As Figs. 3 e 4 mostram a comparação das séries temporais das observações da velocidade média mensal e direção média mensal do vento, respectivamente, fornecidas pelo produto BSW na exata localização das boias oceânicas, com as séries temporais obtidas por cada uma das três boias do projeto PIRATA, para o período de 15 de dezembro de 1997 à 15 de setembro de 2011.

Camargo e Sentelhas (1997) propõem que, ao se correlacionar os valores estimados e os observados experimentalmente, sejam considerados o coeficiente de correlação (R) de Pearson e o índice de concordância (IC) de Willmott. O índice de correlação (R) é um bom indicador de precisão uma vez que, em sua expressão, estão relacionados os dados estimados e observados. Ainda segundo os autores, a exatidão está relacionada ao afastamento dos valores estimados em relação aos observados; matematicamente, esta aproximação é dada pelo índice de concordância, onde seus valores variam de zero, para nenhuma concordância, a 1 para a concordância perfeita.Além destes índices, são mostrados na Fig. 3 o viés, o erro absoluto, ERRA, e o erro quadrático médio, ERRQM. Observa-se nas Figs. 3(a), 3(b) e 3(c), que ambos os conjuntos de dados se ajustam satisfatoriamente, tendo sido obtido viés insigni- 


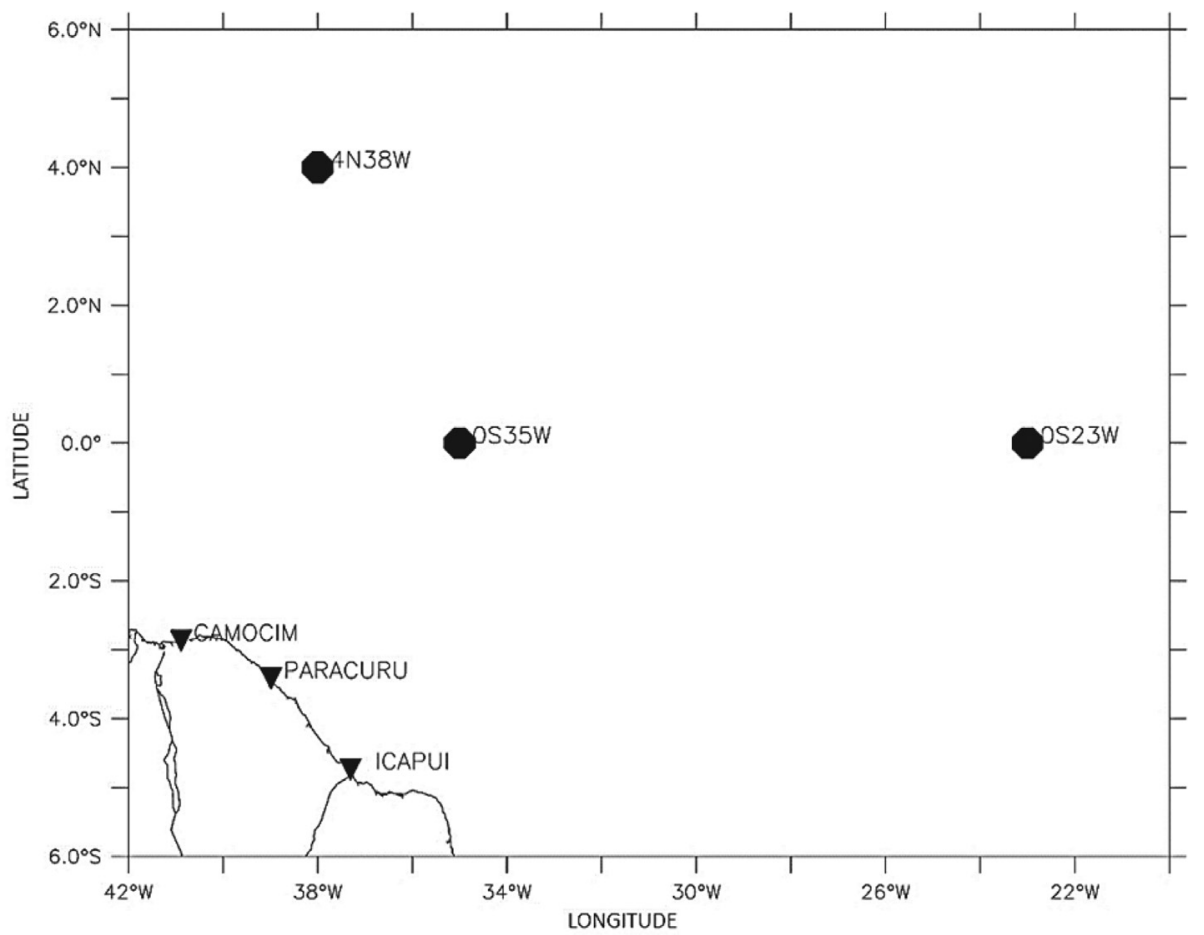

Figura 1 - Localização das boias oceânicas e torres anemométricas utilizadas para validação dos dados.

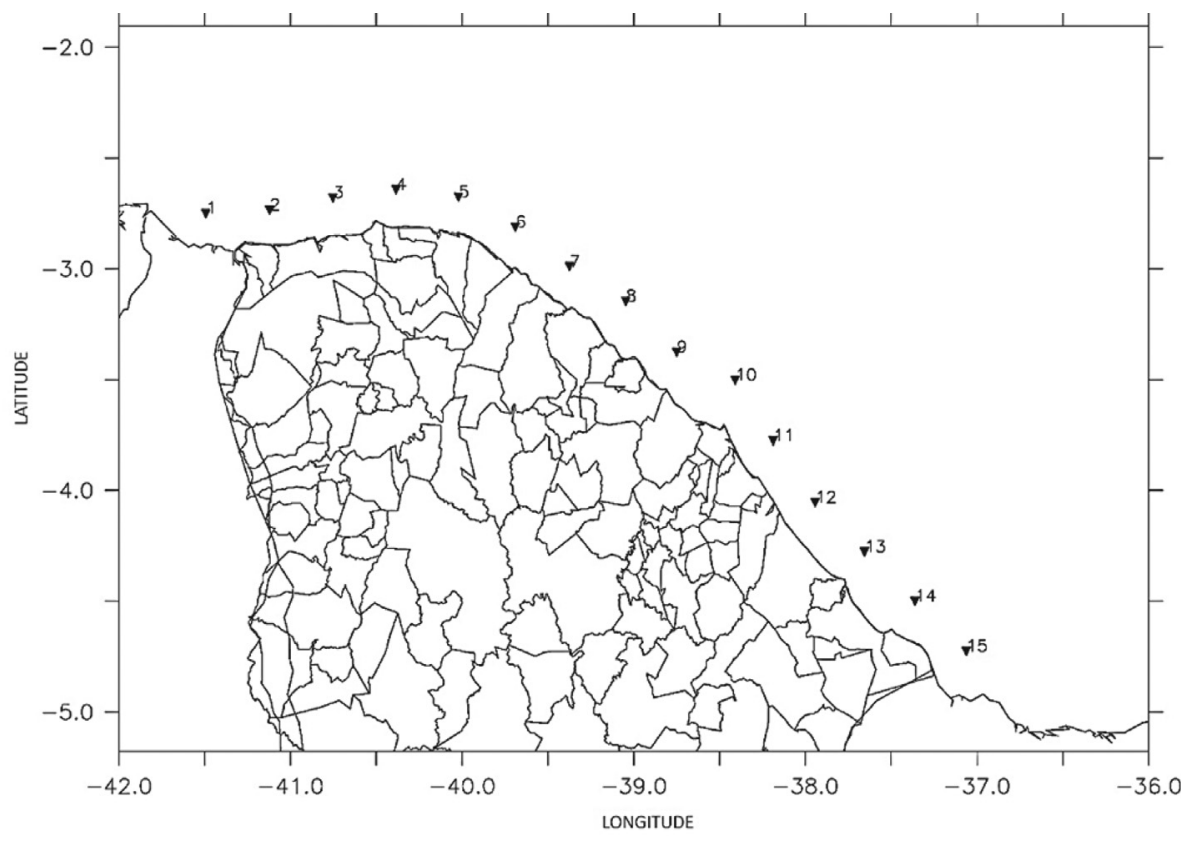

Figura 2 - Localização dos quinze pontos de análise ao longo da costa litorânea do Ceará.

ficante entre as duas séries. Os índices estatísticos revelam portanto, uma boa performance, indicando assim uma forte associação significativa positiva entre os dados de velocidade.

Mesmo que o método de determinação dos ventos pelo produto BSW fosse isento de erros ainda não poderíamos esperar perfeita concordância na intensidade dos ven- tos, uma vez que o produto dos satélites estima o vento médio em uma área (de grade $0,25^{\circ} \times 0,25^{\circ}$ ) enquanto que a boia oceânica fornece o vento medido em um ponto de localização exata. Além disso, a correção logarítmica aplicada ao nivelar os dados de vento medidos nas boias do projeto PIRATA com os do BSW considerou a atmosfera estaticamente neutra, pressuposto este frequentemente vio- 


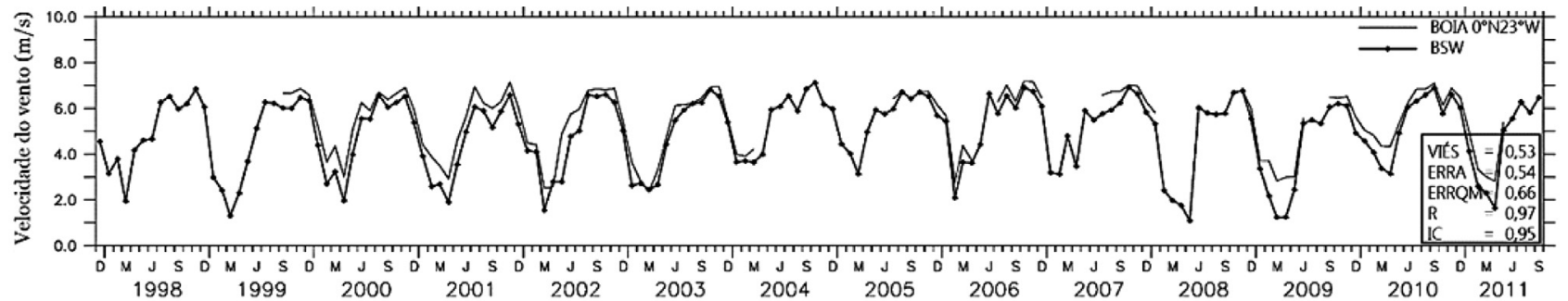

(a)

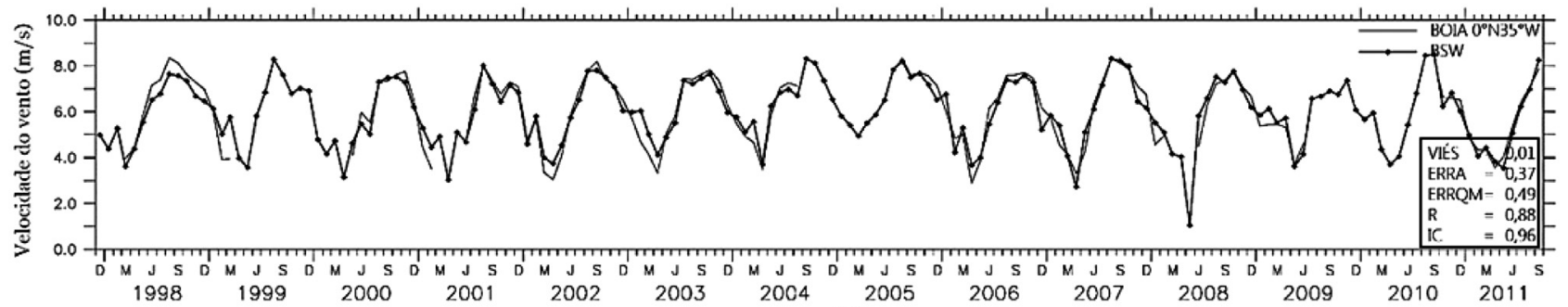

(b)

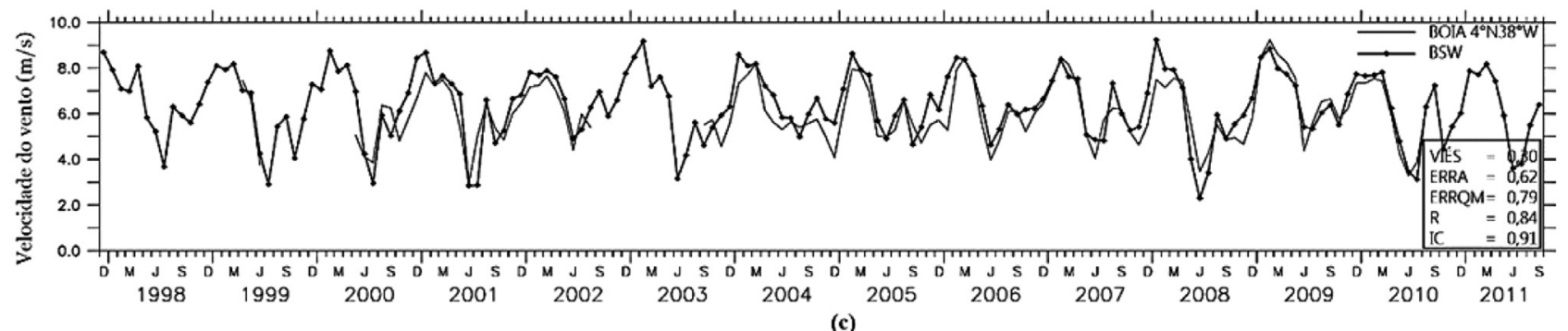

Figura 3 - Séries temporais das velocidades médias mensais do vento das boias oceânicas e BSW, relativas à altura de $10 \mathrm{~m}:$ (a) $\mathrm{Boia} 0^{\circ} \mathrm{N}, 23^{\circ} \mathrm{W}(\mathrm{b}) 0^{\circ} \mathrm{N}$, $35^{\circ} \mathrm{W}(\mathrm{c}) 4^{\circ} \mathrm{N}, 38^{\circ} \mathrm{W}$.
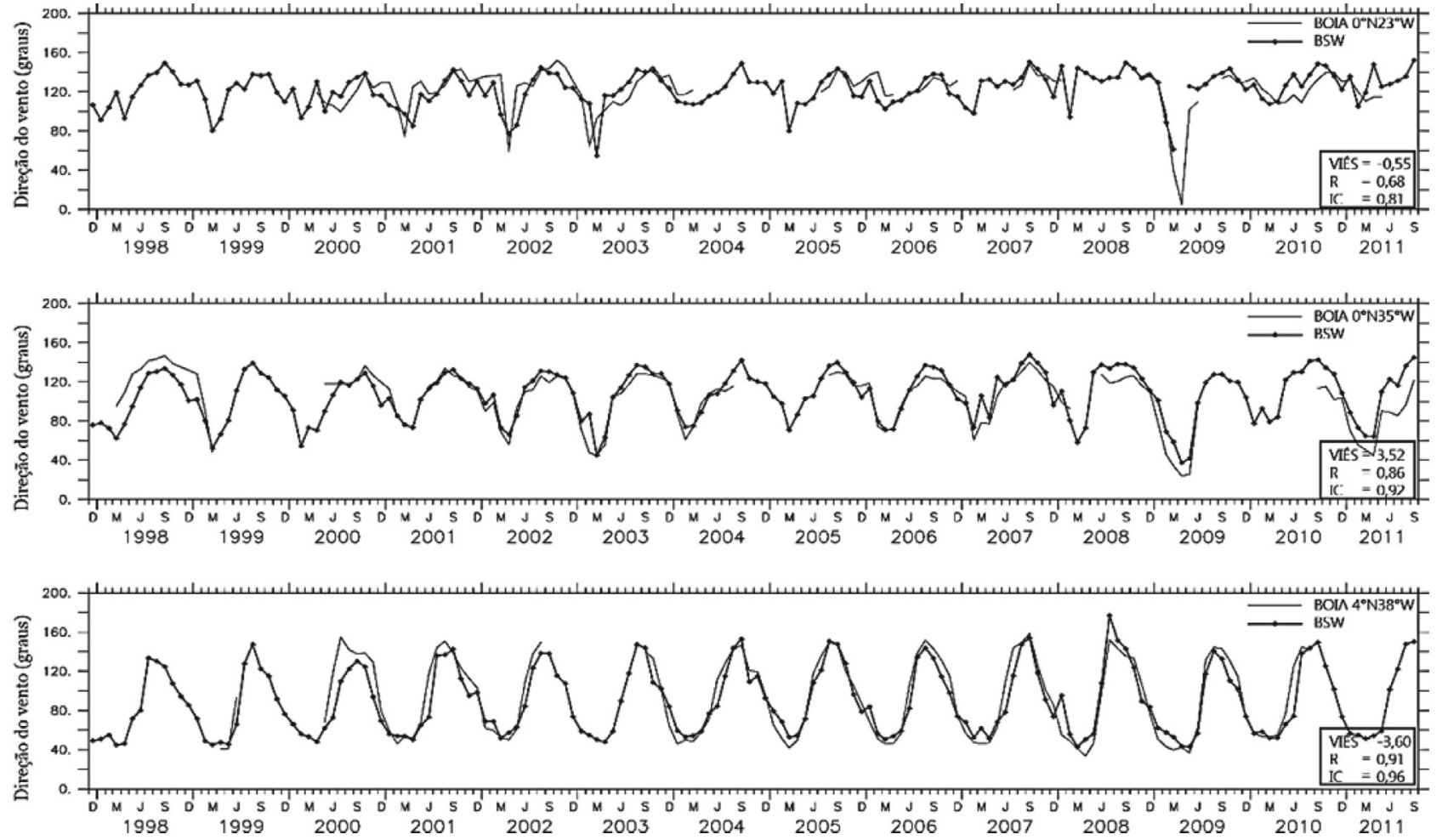

Figura 4 - Séries temporais das direções médias mensais do vento das boias oceânicas e BSW, relativas à altura de $10 \mathrm{~m}:$ (a) Boia $0^{\circ} \mathrm{N}, 23^{\circ} \mathrm{W}$ (b) $0^{\circ} \mathrm{N}$, $35^{\circ} \mathrm{W}(\mathrm{c}) 4^{\circ} \mathrm{N}, 38^{\circ} \mathrm{W}$. 
lado na atmosfera real. As concordâncias significativas entre boias e o BSW para os valores médios mensais de direção do vento, mostrados na Fig. 4 são, no entanto, esperadas. Os satélites não determinam com acurácia a direção dos ventos; no BSW a direção é obtida de reanálises, NCEP2 e ECMWF. Estas reanálises, por sua vez, assimilam os ventos das boias, ou seja, as direções de vento das boias estão, de certa forma, já inseridas no BSW.

\subsubsection{Dados BSW vs. torres anemométricas}

Todas as comparações feitas nesta seção são entre os ventos medidos em torres litorâneas e o vento estimado pelo BSW à $10 \mathrm{~m}$, no ponto da grade oceânica mais próximo e a leste da respectiva torre.

As Figs. 5(a), 5(b) e 5(c) comparam a intensidade dos ventos das torres de Paracuru, Camocim e Icapuí, respectivamente a $20 \mathrm{~m}, 20 \mathrm{~m}$ e $40 \mathrm{~m}$ de altura, com o vento BSW.
Os principais índices estatísticos são mostrados nas figuras. As comparações não objetivam quantificar a coincidência dos dados - os ventos das torres e do BSW são obtidos sobre superfícies e níveis verticais diferentes - e sim, verificar a capacidade dos ventos BSW de reproduzir as tendências observadas na intensidade dos ventos de baixos níveis costeiros. As séries temporais dos ventos BSW para Camocim e Icapuí foram deslocadas verticalmente pela remoção do viés médio relativo às respectivas torres, para facilitar a comparação das tendências. Para estas duas torres, os índices IC e R são calculados após a remoção do viés do vento BSW. Os índices ERRA e ERRQM para as três torres são calculados para os dados brutos não manipulados. Dos gráficos se identificam visualmente 1) uma boa concordância entre máximos e mínimos locais, principalmente para Paracuru e 2) esta concordância é menor nos meses mais chuvosos de março a maio e maior no semestre seco -

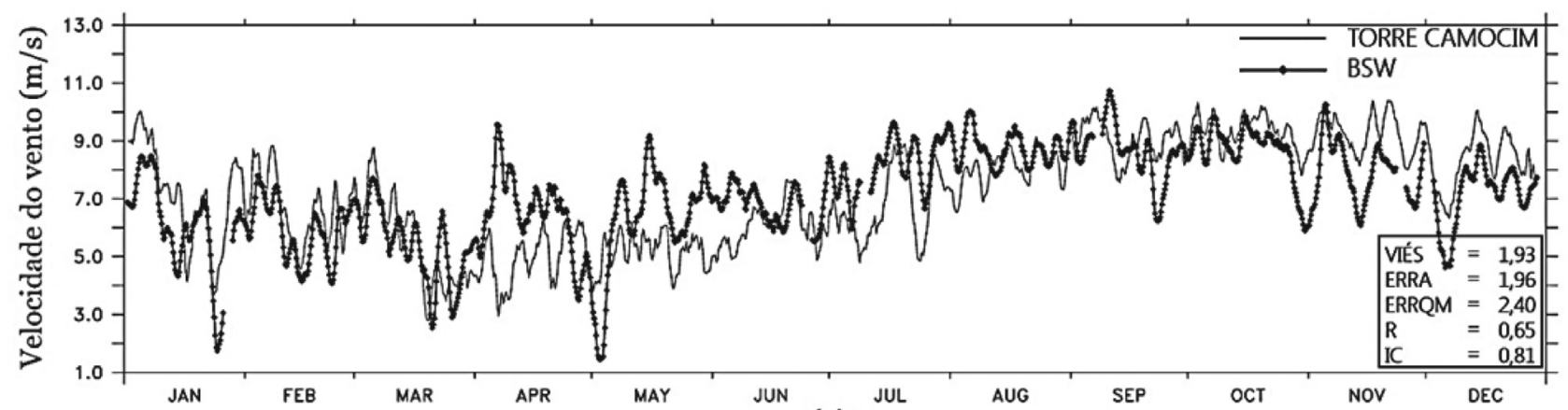

(a)

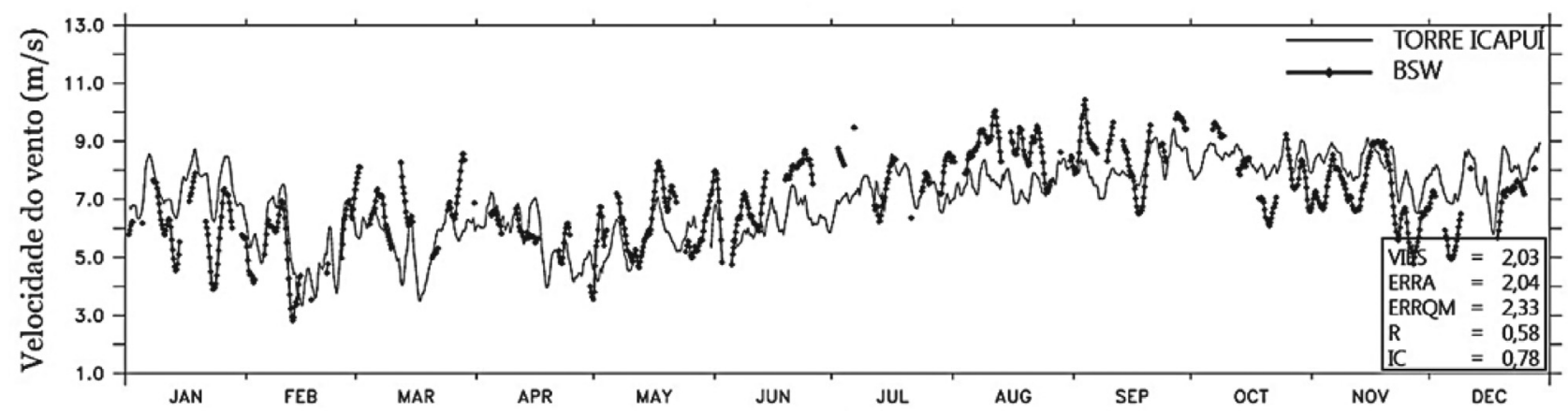

(b)

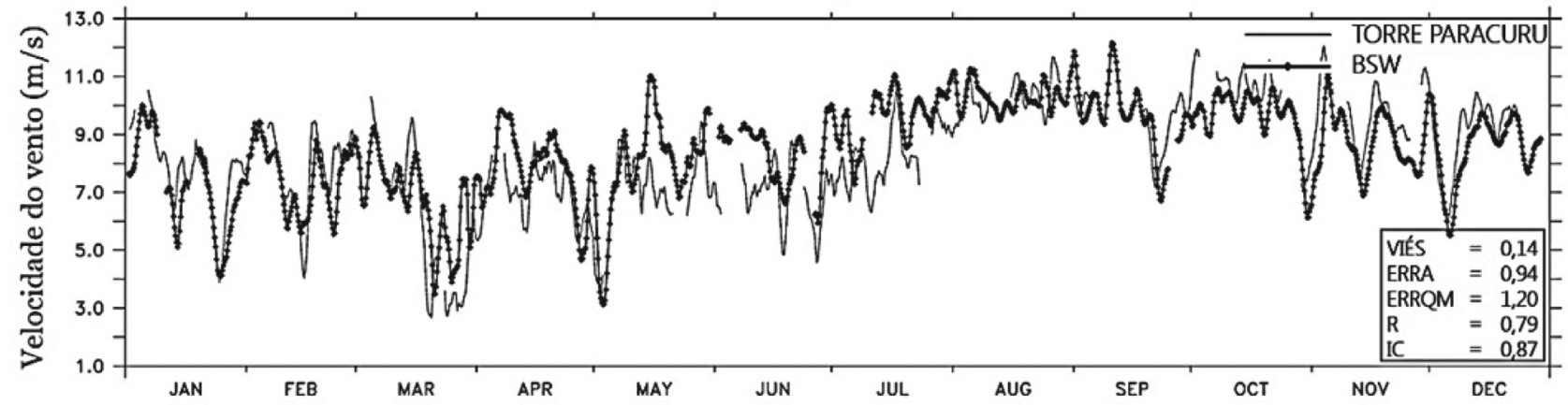

(c)

Figura 5 - Séries temporais das velocidades médias mensais do vento das torres e BSW, relativas à: (a) Torre de Camocim (2005) (b) Torre de Icapuí (2007) (c) Torre de Paracuru (2005). Para as torres de Camocim e Icapuí foram subtraídos os vieses médios dos anos referidos. 
segundo semestre. O viés, ERRA e ERRQM acentuados são esperados uma vez que ventos de torre e BSW não são medidos na mesma superfície e nem no mesmo nível.

As Figs. 6(a) e 6(b) mostram as velocidades médias entre os ventos das Torres de Paracuru e Camocim e o BSW nos meses de março a junho, que compreende o período chuvoso de março a maio, e de agosto a novembro, que compreende o período seco de agosto a outubro. Destaca-se

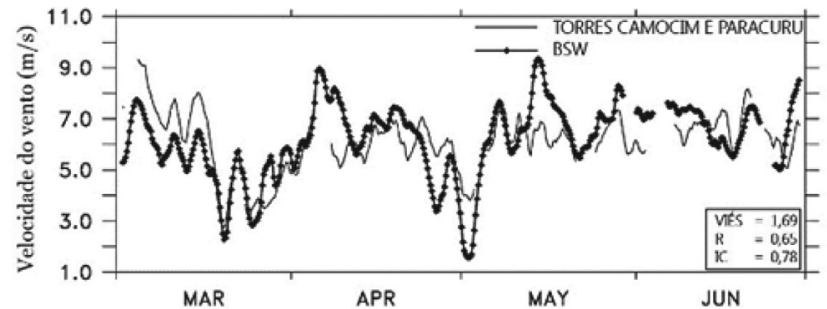

(a)

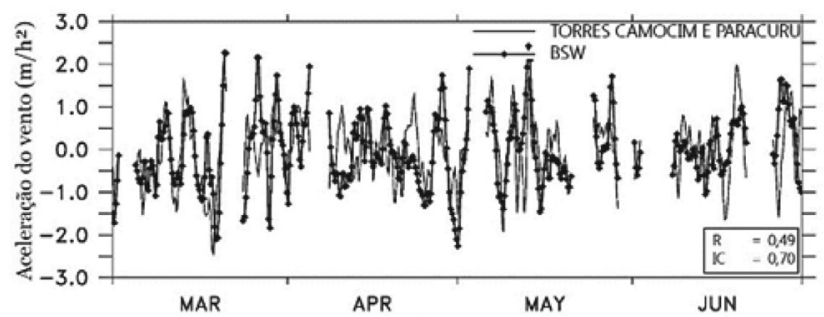

(c) a boa concordância entre as tendências, melhor no período seco, como revelado pela melhor concordância entre extremos locais e menor valor do viés. As concordâncias são mais destacadas entre as acelerações, mostradas nas Figs. 6(c) e 6(d) para os mesmos períodos, o que sugere forte acoplamento entre ventos costeiros e oceânicos.

As Figs. 7(a) e 7(b) mostram as acelerações médias de Paracuru e Camocim, para os ventos das torres e do BSW às

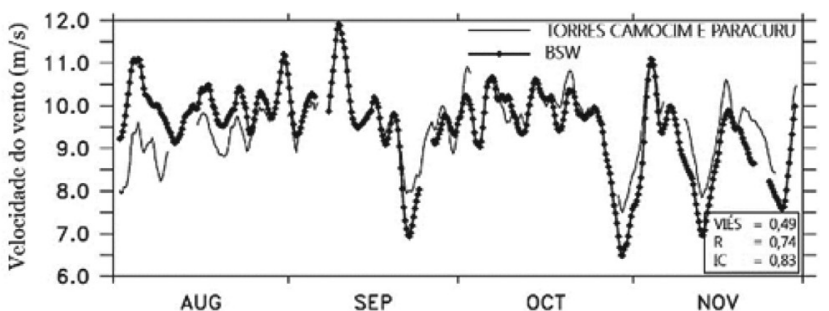

(b)

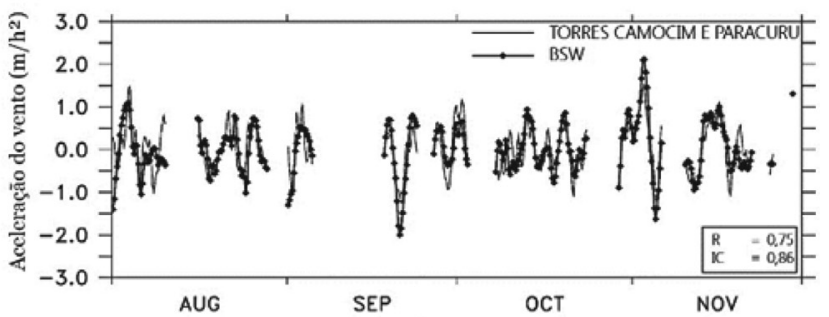

(d)

Figura 6 - Séries temporais para as localidades de Paracuru e Camocim: (a) velocidades médias ( $\mathrm{m} / \mathrm{s}$ ) março a junho (compreende o período chuvoso) (b) velocidades médias $(\mathrm{m} / \mathrm{s})$ de agosto a novembro (compreende o período seco) (c) acelerações médias $\left(\mathrm{m} / \mathrm{h}^{2}\right)$ março a junho (compreende o período chuvoso) (d) acelerações médias $\left(\mathrm{m} / \mathrm{h}^{2}\right)$ de agosto a novembro (compreende o período seco).

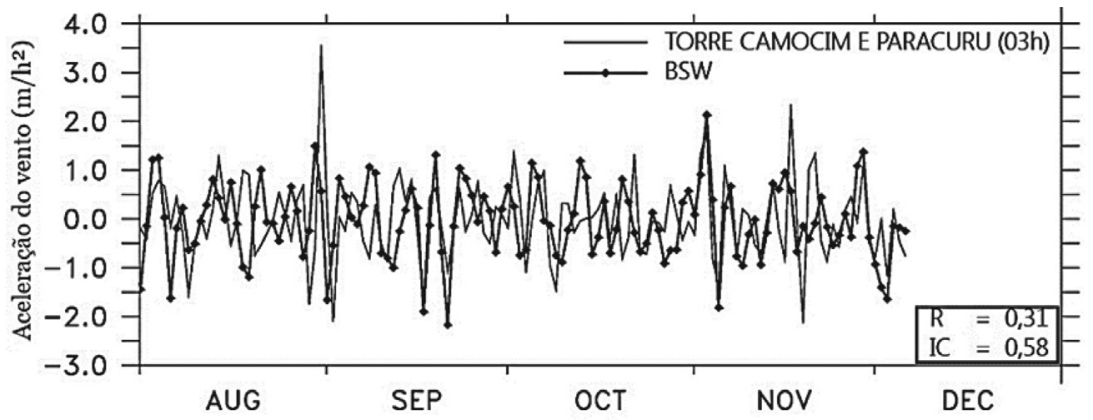

(a)

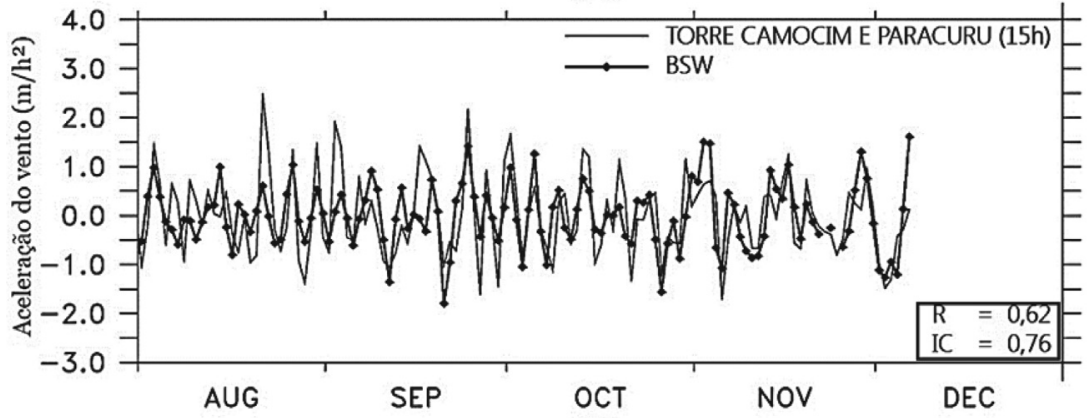

(b)

Figura 7 - Séries temporais das acelerações médias $\left(\mathrm{m} / \mathrm{h}^{2}\right)$ mensais do vento para as localidades de Camocim e Paracuru e BSW no segundo semestre (agosto-dezembro) às: (a) $03 \mathrm{~h}$ (b) $15 \mathrm{~h}$. 
03 e $15 \mathrm{~h}$, respectivamente, entre agosto e novembro. As melhores concordâncias ocorrem às $15 \mathrm{~h}$. Neste horário a brisa marítima é atuante, com direção média dos ventos medidos pelas torres, entre agosto e setembro a $20 \mathrm{~m}$, de $61^{\circ}$. A componente onshore do vento, destacada neste horário, acentua o acoplamento entre torre e o BSW. Às $03 \mathrm{~h}$ a direção média dos ventos medidos pelas torres é de $120^{\circ}$, portanto, com acentuada componente offshore, o que reduz a concordância entre torre e BSW neste horário.

As concordâncias das tendências entre ventos costeiros e oceânicos evidenciadas pelas Figs. 5, 6, e 7, mostram que 1) o BSW consegue reproduzir as tendências observadas nos ventos costeiros e 2) os ventos ao longo da costa são determinados e modulados pelos ventos oceânicos. Estas concordâncias são garantidas pelas baixas altitudes do relevo no litoral. A inclinação da costa relativa a linha do Equador e a direção média dos alísios de baixos níveis, garantem que os ventos costeiros sejam predominantemente onshore, mesmo nos horários em que a brisa terrestre é mais intensa, o que contribui para acentuar o acoplamento entre ventos costeiros e oceânicos. No primeiro semestre a atividade convectiva mais acentuada reduz os gradientes de pressão terra-oceano, enfraquecendo as brisas, reduzindo o acoplamento entre vento costeiro e oceânico, em consequência, as concordâncias entre estes ventos são menores neste período em comparação com o semestre seco como destacado nos gráficos da Fig. 6.

\subsection{Estudo da variabilidade dos ventos climatológicos}

Como a climatologia dos ventos no Litoral Cearense está diretamente relacionada ao retorno sazonal da Zona de
Convergência Intertropical (ZCIT) é informativo descrever a sazonalidade da atividade convectiva: no litoral cearense, de dezembro a janeiro temos a pré-estação chuvosa, quando acontecem os primeiros registros de chuvas mais intensas. A estação chuvosa vai de fevereiro a maio, período em que a ZCIT determina a maior parte da precipitação e em que ocorrem os ventos mais fracos do ano, junho é o mês de pós-estação, quando a migração para o norte da ZCIT é acompanhada do aumento dos ventos e em julho inicia-se o período seco, em virtude da baixa média mensal de chuva observada. A climatologia dos ventos BSW no Litoral Cearense utilizando dados mensais de junho de 1987 a setembro de 2011 é mostrada na Fig. 8. A média climatológica também foi realizada para os meses mais chuvosos, de março a maio, conforme mostra a Fig. 9(a), e para os meses mais secos, de agosto a outubro, mostrada na Fig. 9(b).

A Fig. 8 mostra que, em média, os ventos climatológicos mais intensos ocorrem nos litorais do Ceará e RN, principalmente nos extremos leste e oeste do Litoral Cearense. A variabilidade espacial ao longo da costa é pequena, menor que $1 \mathrm{~m} / \mathrm{s}$, destacando-se duas regiões de ventos mais intensos que coincidem com as concavidades nos extremos leste e oeste do Ceará, em torno de $37^{\circ} \mathrm{W}$ e $41^{\circ}$ $\mathrm{W}$, respectivamente, doravante chamadas de concavidades leste e oeste. Estes máximos se devem provavelmente ao aumento da convergência dos ventos de brisas nas concavidades facilitado pelos fluxos médios quase paralelos a costa.

Durante o período seco - agosto a outubro (ASO), observa-se na Fig. 9(b), assim como na média climatológica na Fig. 8, que o gradiente da intensidade do vento ao

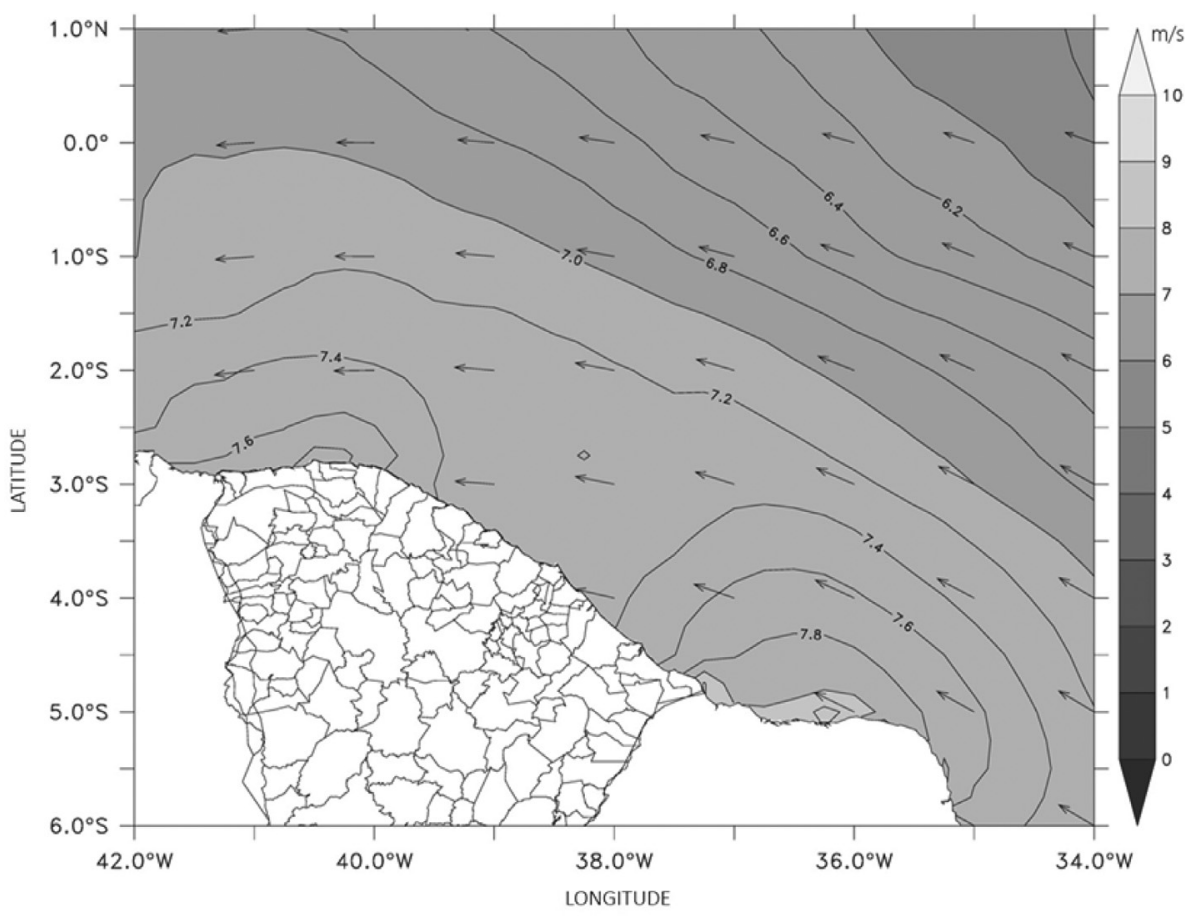

Figura 8 - Velocidade média (m/s) dos ventos climatológicos estimados pelo produto BSW para a série histórica de 15-JUL-1987 à 15-SET-2011. 


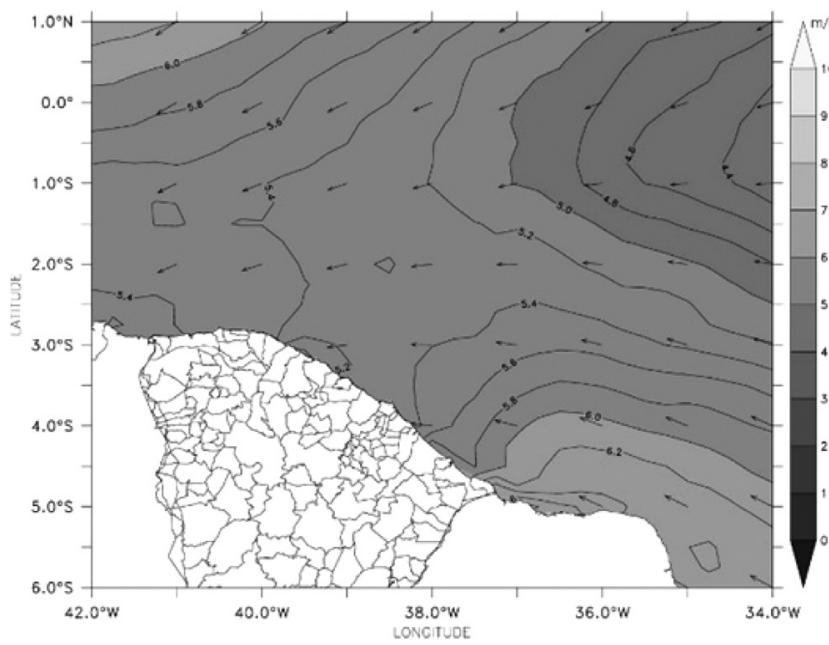

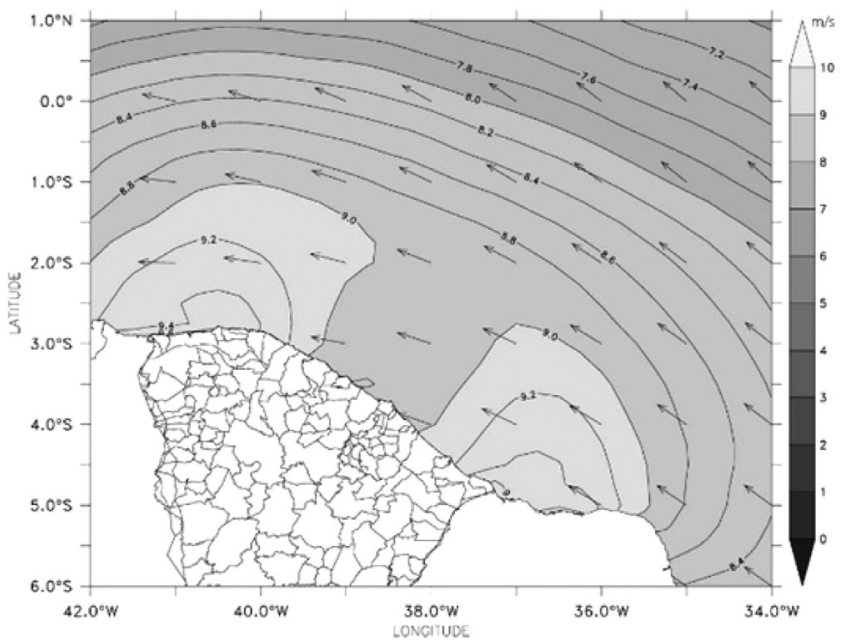

Figura 9 - Velocidade média $(\mathrm{m} / \mathrm{s})$ dos ventos climatológicos estimados pelo produto BSW para o período de (a) março a maio (b) agosto a outubro.

longo da costa é da Região Metropolitana de Fortaleza (RMF) para as concavidades leste e oeste. Neste período, o efeito da intensificação dos ventos nestas concavidades extremas é mais destacado. No período chuvoso - março a maio (MAM) estes máximos são ligeiramente mais intensos na concavidade leste, produzindo gradiente de ventos maiores da RMF para a concavidade leste, Fig. 9(a).

A Fig. 10 mostra a variabilidade sazonal dos ventos climatológicos estimada pelo produto BSW e o posionamento médio da ZCIT, para os dados de junho de 1987 a setembro de 2011, de março a maio (período chuvoso), e de agosto a outubro (período seco).

As linhas tracejada e contínua indicam as localidades onde a velocidade meridional se anula, $V_{y}=0$, separando os ventos de Nordeste acima da linha, dos de Sudeste, abaixo da linha. As linhas coincidem aproximadamente, com o posicionamento médio da ZCIT em MAM e ASO, respectivamente. Fora da região delimitada por estas linhas a variabilidade sazonal é baixa na intensidade e principalmente na direção dos ventos superficiais, como observado também na Fig. 9. Na concavidade oeste a sazonalidade na inten-

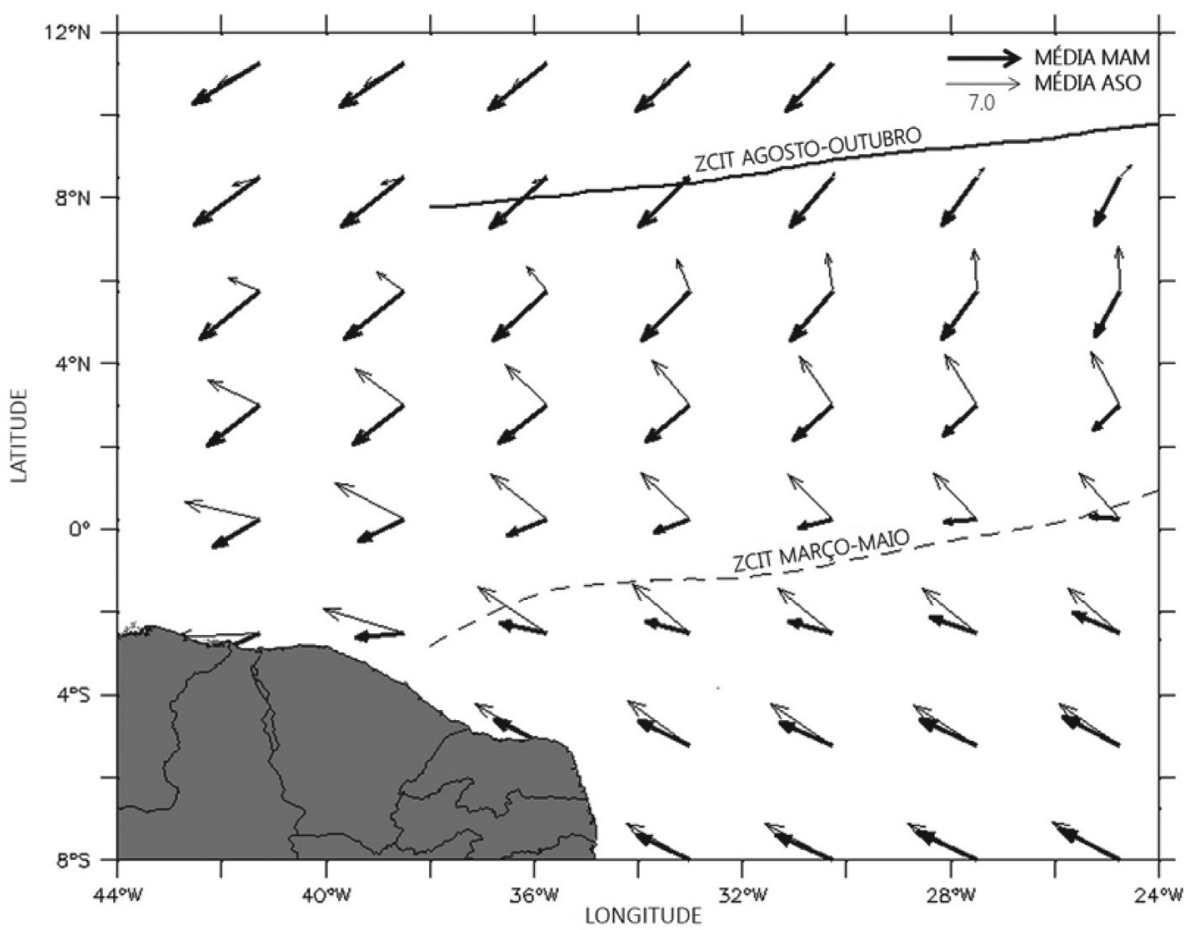

Figura 10 - Ventos climatológicos estimados pelo produto BSW para MAM (vetor negritado) e ASO (vetor não negritado). 
sidade e direção dos ventos é mais destacada do que na concavidade leste, provavelmente, pelo fato da extremidade da ZCIT no período chuvoso (linha tracejada da Fig. 10) situar-se, em média, entre a concavidade oeste e a RMF, produzindo maior variabilidade sazonal nessa região.

As Figs. 11(a) e 11(b) mostram, respectivamente, as séries temporais dos valores médios de intensidade e direção dos ventos BSW, na região de coordenadas $5^{\circ} \mathrm{S}, 1^{\circ} \mathrm{Ne}$ $42^{\circ} \mathrm{W}, 35^{\circ} \mathrm{W}$, média climatológica para todos os meses do ano. A região destacada abrange toda a plataforma continental cearense da concavidade leste a oeste. Como os ventos oceânicos (BSW) no Ceará estão estreitamente correlacionados com os ventos costeiros pode-se tomar a amplitude das variações observadas nas Figs. 11(a) e 11(b) como uma aproximação das variações dos ventos costeiros.

A migração sazonal da ZCIT produz grande variação na intensidade dos ventos superficiais entre os períodos chuvoso e seco. Os meses de março a maio apresentam os menores valores médios mensais de velocidade do vento com mínimo de $5,1 \mathrm{~m} / \mathrm{s}$ em abril, conforme observado na Fig. 11(a). Os maiores valores médios mensais de velocidade ocorreram de agosto a setembro, com máximo de $8,8 \mathrm{~m} / \mathrm{s}$. Neste período, ventos alísios se intensificam soprando quase constantes, predominando velocidades superiores a $8 \mathrm{~m} / \mathrm{s}$ (o Atlas Eólico do Ceará, em 2001, revelou velocidades superiores a $10 \mathrm{~m} / \mathrm{s}$ a partir de $40 \mathrm{~m}$ de altura). Na Fig. 11(b) observa-se que a variabilidade mensal da direção do vento é menor para o período seco se comparada com o padrão médio no período chuvoso, apresentando amplitude próxima de $13^{\circ} \mathrm{em} \mathrm{ASO} \mathrm{e} \mathrm{superior} \mathrm{a} 20^{\circ} \mathrm{em}$ MAM. Esta baixa variabilidade mensal na direção do vento durante o período seco, também observada na intensidade, é um critério muito importante para fins de aproveitamento eólico, sendo um fator relevante para a instalação de aerogeradores (Costa e Lyra, 2012). A Fig. 11(b) mostra ainda a grande sazonalidade na direção dos ventos costeiros com ângulos mínimos em março (vento de Nordeste) e máximos em julho (ventos de Sudeste). Nota-se ainda, defasagem de aproximadamente um mês entre os dados de velocidade e direção, enquanto a velocidade média mínima do vento é estimada em abril, sua direção média mínima é observada em março. Esta defasagem também observada nas séries temporais de torres e Plataformas de Coletas de Dados costeiras (não mostrada neste trabalho), é decorrente provavelmente de alguma defasagem maior, em escala sinótica, entre a localização de máxima precipitação e da região de máxima convergência.

\subsection{Estudo da variabilidade interanual}

Como estratégia para o estudo da variabilidade interanual dos ventos oceânicos no Litoral Cearense comparam-se dois anos consecutivos, um bastante chuvoso, 2009, e outro seco, 2010, sem considerar possíveis influências de eventos de grande escala, como El Niño, ou La Niña, sobre essa variabilidade.

A Fig. 12(a) mostra os ventos BSW no trimestre chuvoso março-maio para os anos de 2009 e 2010. A Fig. 12(b) mostra os ventos médios BSW no trimestre seco agosto-outubro para 2009 e 2010. Os vetores para 2009 estão negritados, os vetores para 2010, não estão negritados.

Observa-se na Fig. 12(a) uma variabilidade significativa na intensidade e, principalmente, na direção dos ventos superficiais entre os dois anos para o trimestre mar-

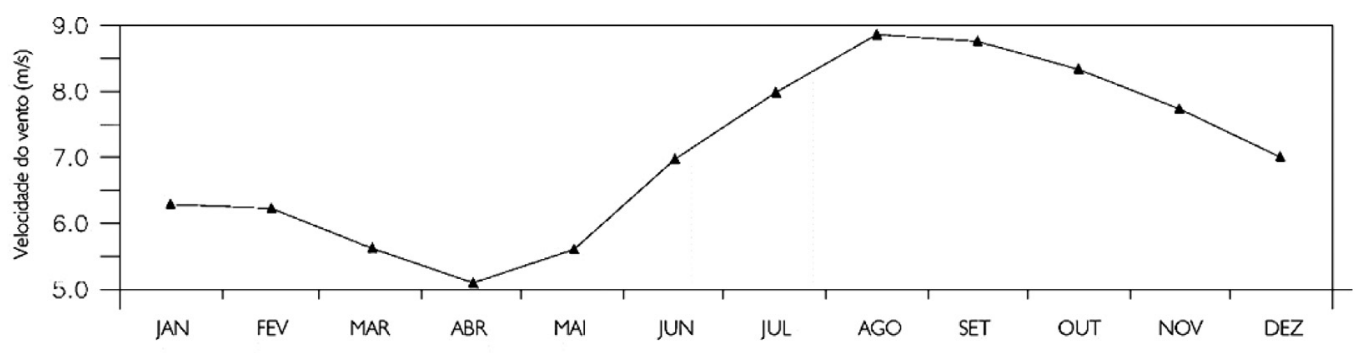

(a)

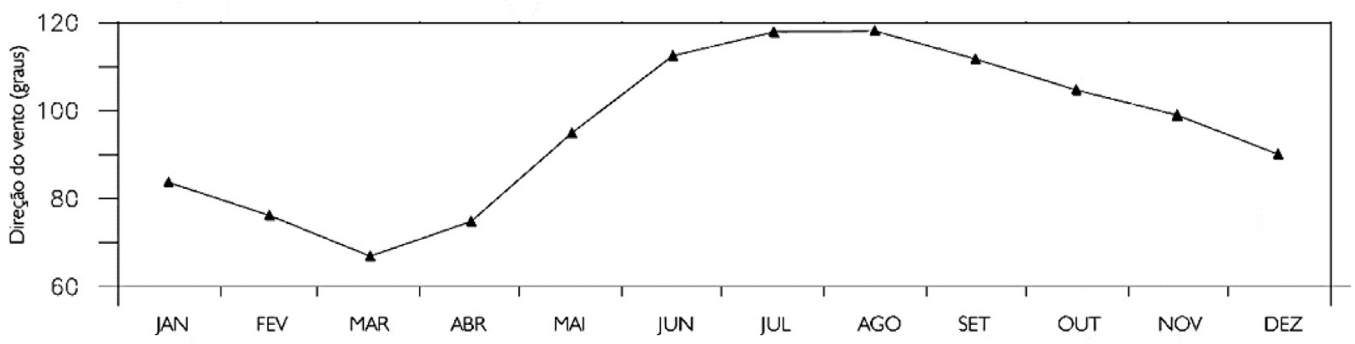

(b)

Figura 11 - (a) Velocidade média (m/s) mensal e (b) direção média (graus) mensal dos ventos climatológicos estimados pelo produto BSW para a série histórica de 15-JUL-1987 à 15-SET-2011. 

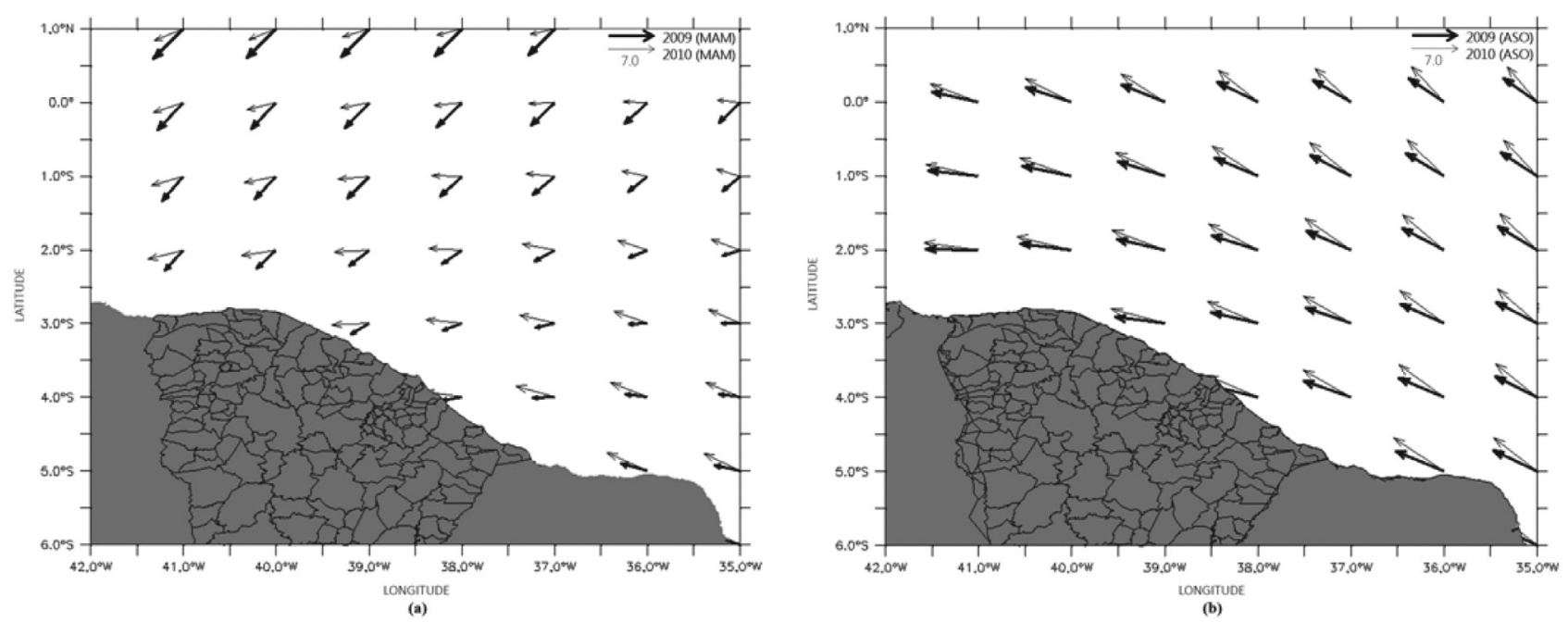

Figura 12 - Ventos climatológicos estimados pelo produto BSW para 2009 (vetor negritado) e 2010 (vetor não negritado) (a) de março a maio (b) de agosto a outubro.

ço-maio, enquanto que na Fig. 12(b), que representa o período seco, a variabilidade interanual é baixa na intensidade e também na direção dos ventos superficiais. Em março-maio do ano chuvoso (2009), os ventos na concavidade oeste sopram de Nordeste e na concavidade leste sopram de Leste. A variabilidade interanual na direção dos ventos no período chuvoso é maior no litoral oeste do Ceará. Na estação seca, os ventos sopram quase paralelo a costa nas duas concavidades. Neste período, a interação destes ventos médios com o fenômeno de brisa, intensificam os ventos nas concavidades resultando nos ventos mais intensos do litoral do Ceará.

Para entender a dinâmica dos ventos oceânicos costeiros selecionamos quinze pontos ao longo do litoral do Ceará centrados na caixa de grade do BSW mais próxima à costa e mostrados na Fig. 2. No eixo horizontal nos gráficos da Fig. 13 são enumeradas estas quinze localidades em ordem crescente da concavidade oeste para a leste. Nas Figs. 13(a) e 13(b) são mostrados, respectivamente, os valores da intensidade e direção dos ventos nestas localidades, para os dados climatológicos de julho de 1987 a setembro de 2011 e as médias dos dados mensais para os anos inteiros de 2009 e 2010.

A Fig. 13(a) mostra que o gradiente climatológico na intensidade dos ventos ao longo da costa se dirige da RMF (ponto 10 do eixo horizontal) para as concavidades, como também pode se observar na Fig. 8. Este gradiente se mantém, com variações de intensidade, nos anos seco e chuvoso. As amplitudes das variações das intensidades dos ventos ao longo da costa, mostradas nos três gráficos da Fig. 13(a), $\Delta u$, são parecidas e menores que $1 \mathrm{~m} / \mathrm{s}$. Para a direção dos ventos, o padrão médio, Fig. 13(b), é de ventos de Nordeste na concavidade oeste e ventos de Sudeste na concavidade Leste com variações de aproximadamente $30^{\circ}$ ao longo da costa. Como causa deste padrão concorrem (a) a inclinação da costa relativa ao Equador, (2) as variações desta inclinação nas concavidades leste e oeste e (3) as brisas marítima e terrestre. Este padrão mostra pouca variabilidade interanual. Os ventos, no entanto, apresentam componente de Sudeste mais destacada no ano seco de 2010. A componente de Nordeste acentua-se no ano chuvoso de 2009. Estas variações são causadas pela variabilidade interanual da posição meridional da ZCIT no período chuvoso.

A Fig. 13(c) mostra as diferenças entre a intensidade dos ventos entre 2010 e 2009 para os trimestres mais chuvosos, março a maio, e mais seco, setembro a novembro. Na Fig. 13(d) as mesmas diferenças são mostradas para a direção dos ventos. Nestes gráficos observa-se que no período chuvoso a variabilidade interanual na intensidade e direção dos ventos é consideravelmente maior que no período seco. As menores variações nos meses secos resultam em maior previsibilidade dos padrões de ventos para este período. As menores variações interanuais ocorrem na concavidade oeste.

\section{Conclusões}

Neste trabalho os ventos a $10 \mathrm{~m}$ estimados por satélites, BSW, são validados a partir dos dados de ventos coletados por boias do projeto PIRATA e torres anemométricas ao longo do litoral cearense. A concordância significativa com as boias mostra que o BSW consegue reproduzir com acurácia os padrões observados de mesoescala dos ventos alísios. Comparações entre ventos medidos por torres anemométricas instaladas no litoral cearense e o vento BSW, no ponto da grade oceânica mais próximo e a leste da respectiva torre, mostram que os ventos marítimos do BSW reproduzem as tendências observadas nos ventos das torres. Esta concordância entre torres e ventos BSW não só evidencia a acurácia destes nas vizinhanças da costa como também mostram que os ventos marítimos ao 


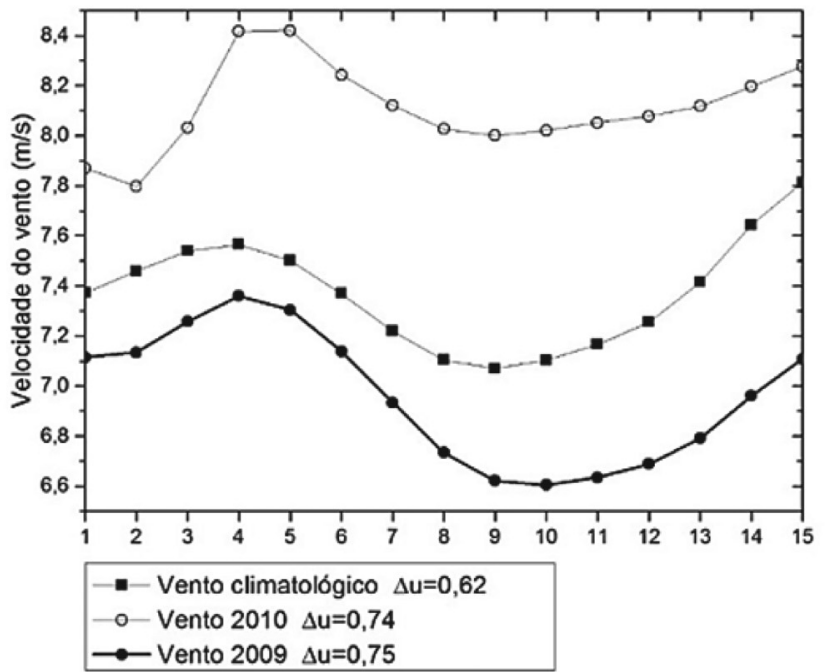

(a)

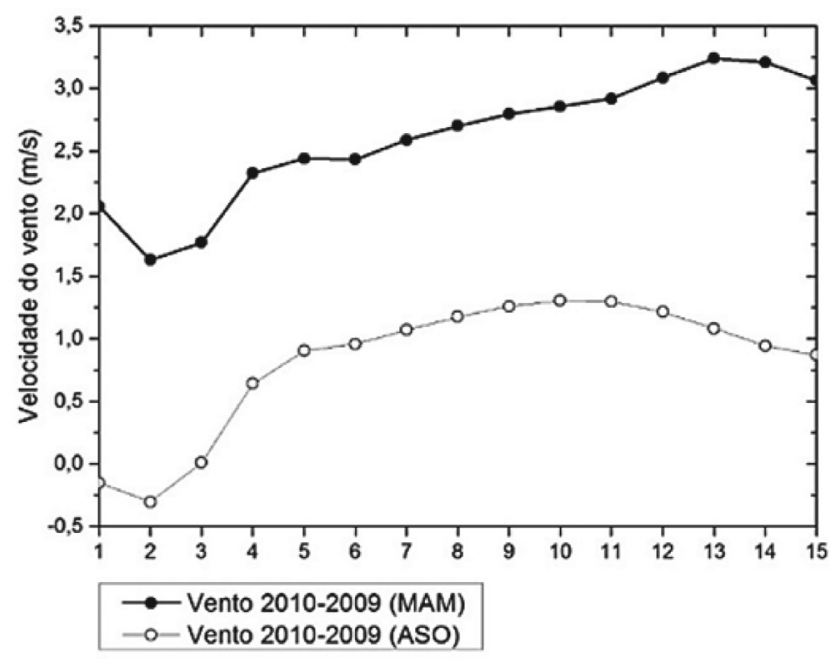

(c)

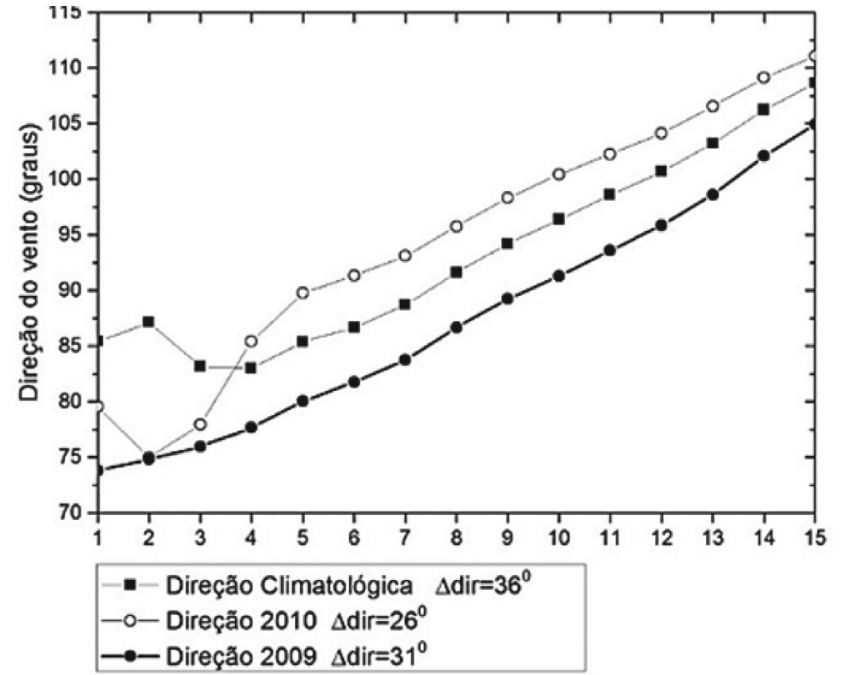

(b)

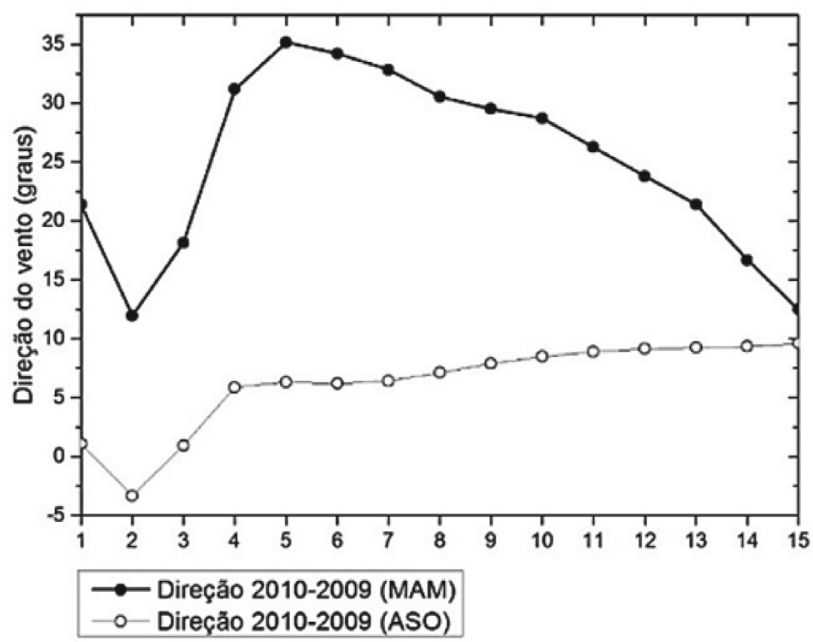

(d)

Figura 13 - Climatologia dos dados mensais de julho de 1987 a setembro de 2011 e médias dos dados mensais para os anos inteiros de 2009 e 2010 (a) intensidade do vento $(\mathrm{m} / \mathrm{s})$ (b) direção do vento (graus) (c) diferenças das intensidades (m/s) (d) diferenças das direções dos ventos (graus).

longo do litoral cearense determinam e modulam os ventos costeiros, mesmo nos horários em que a brisa terrestre é mais intensa. Esta modulação dos ventos costeiros pelos marítimos possibilita a utilização dos ventos BSW como informação inicial e de fronteira confiável em modelos que estimam potencial eólico onshore e offshore.

Verificada sua acurácia, os ventos BSW são utilizados para estudar as variabilidades espacial dos ventos ao longo da costa do Ceará nas escalas climática, interanual e sazonal. Os ventos climatologicamente mais intensos são observados nos extremos leste e oeste do litoral cearense e são, provavelmente, decorrentes do acoplamento entre os ventos de grande escala quase paralelos à costa e as brisas marítima e terrestre, intensificadas pelo formato côncavo da costa nestes extremos. As maiores variações sazonais na intensidade e direção dos ventos de baixos níveis ocorrem na região localizada entre os extremos de migração meridi- onal da ZCIT: em torno de $8^{\circ} \mathrm{N}$, entre agosto e outubro, e $2{ }^{\circ} \mathrm{S}$ entre março e maio, o que deixa o litoral cearense com as maiores variações do litoral nordestino. Ao se comparar dois anos consecutivos, porém, atípicos e com padrões climatológicos bastante divergentes, um chuvoso e um seco, 2009 e 2010, respectivamente, conclui-se que o semestre chuvoso é responsável pela maior parte da variabilidade interanual elevada nos ventos de baixos níveis, ou seja, os ventos nestes dois anos mostram suas maiores diferenças durante o primeiro semestre e apresentam destacada concordância nos meses mais secos. As intermitências da atividade convectiva, sua complexidade e influências sobre os fluxos de baixos níveis dificultam a previsão dos ventos de mesoescala no período chuvoso.

As combinações dos fluxos de grande escala, brisas, inclinação da costa relativa ao Equador e o formato côncavo nos extremos leste e oeste do Estado produzem varia- 
ções na intensidade e direção ao longo da costa com ventos preferencialmente de Sudeste na concavidade leste e de Nordeste na concavidade oeste. Para efeito de aproveitamento de energia eólica estas variações ao longo da costa podem ser consideradas pequenas, mesmo no período chuvoso; menores que $1 \mathrm{~m} / \mathrm{s}$.

Em geral, a abordagem a partir de dados de ventos estimados por produto de satélites, pode ser considerada útil para o propósito de um estudo preliminar dos padrões de ventos no litoral do Ceará, tornando-se assim, uma ferramenta valiosa na investigação de áreas com potencial offshore/onshore para a geração de energia eólica.

\section{Agradecimentos}

À Coordenação de Aperfeiçoamento de Pessoal de Nível Superior (CAPES), ao Curso de Mestrado Acadêmico em Ciências Físicas Aplicadas (CMACFA) e a Universidade Estadual do Ceará (UECE).

\section{Referências}

CAMARGO, A.P.; SENTELHAS, P.C. Avaliação do desempenho de diferentes métodos de estimativa da evapotranspiração potencial no estado de São Paulo, Brasil. Revista Brasileira de Agrometeorologia, v. 5, n. 1, p. 89-97, 1997.

COSTA, G.B.; LYRA, R.F.F. Análise dos padrões de vento no Estado de Alagoas. Revista Brasileira de Meteorologia, São Paulo, v. 27, n. 1, p. 31-38, 2012. Disponível em:
http://www.scielo.br/scielo.php?script=sci_arttext\&pid=S0 102-77862012000100004. Acesso em: 01 nov. 2016.

ROCHA, N.A.; SCHULTZ, D.; BITTENCOURT, R.; AMARANTE, O.A.C.; SUGAI, M. Estabilização Sazonal da Oferta de Energia Através da Complementaridade Entre os Regimes Hidrológico e Eólico. XV SNPTEE - Seminário Nacional de Produção e Transmissão de Energia Elétrica. Grupo de Planejamento de Sistemas Elétricos. Foz do Iguaçu, PR. Out.1999.

SEINFrA. Atlas do Potencial Eólico do Estado do Ceará. Fortaleza. Secretaria de Infraestrutura do Estado do Ceará, 2001. Disponível em: http://www.seinfra.ce.gov.br/index.php/downloads/category/6-energia. Acesso em: 25 nov. 2016.

TEIXEIRA, R.F.B. O fenômeno da brisa e sua relação com a chuva sobre Fortaleza-CE. Revista Brasileira de Meteorologia, São José dos Campos, v. 23, n. 3, p. 282-291, jan. $2008 . \quad$ Disponível em: http://www.rbmet.org.br/port/revista/revista_busca_resulta do.php. Acesso em: 22 set. 2016.

ZHANG, H.M; REYNOLDS. R.W; BATES, J.J. Blended and gridded high resolution global sea surface winds from multiple satellites: 1987-present. 14th Conference on Satellite Meteorology and Oceanography, Atlanta, GA, American Meteorological Society, Paper 100004. 2006. Disponível em: https://ams.confex.com/ams/Annual2006/webprogram/Pap er100004.html. Acesso em: 31 mar. 2017.

This is an Open Access article distributed under the terms of the Creative Commons Attribution Non-Commercial License which permits unrestricted non-commercial use, distribution, and reproduction in any medium provided the original work is properly cited. 